\title{
Assessment of the Life Cycle Environmental Impact of the Olive Oil Extraction Solid Wastes in the European Union
}

\author{
Angela Cossu, Stefania Degl'Innocenti, Monica Agnolucci*, Caterina Cristani, Stefano Bedini and \\ Marco Nuti
}

Department of Agriculture, Food and Environment (DAFE), University of Pisa, via del Borghetto 80 - 56124 Pisa, Italy

\begin{abstract}
There is an increasing interest in developing sustainable systems in the European Union (EU) to recover and upgrade the solid wastes of the olive oil extraction process, i.e. wet husk. A Life Cycle Environmental Impact Assessment (LCIA) of wet husk has been carried out aiming at facilitating an appropriate Life Cycle Management of this biomass. Three scenarios have been considered, i.e. combustion for domestic heat, generation of electric power, and composting. The Environmental Product Declaration and the ReCiPe method were used for Life Cycle Impact Assessment. Domestic heating and power generation were the most important impact factors in damaging human health, ecosystems, and natural resources depletion. Composting was 2-4 orders of magnitude less impacting than domestic heat and power generation. Considering human health, the impact of climate change, human toxicity and particulate matter formation represented the main impact categories. Considering ecosystems, climate change and natural land transformation were the main impact categories. Within natural resources, fossil fuel depletion was impacted three orders more than metal depletion. Within domestic heating and power generation scenarios, storage of wet husk along with the extraction by organic solvent, and the waste treatment were the most impacting phases for global warming potential, ozone layer depletion, acidification and non renewable fossil resources depletion. The results obtained for the waste disposal have been comparatively assessed with respect to the environmental impact of the olive oil production chain.
\end{abstract}

Keywords: Life cycle management (LCM), life cycle assessment (LCA), life cycle impact assessment (LCIA), olive oil extraction wastes, wet husks, domestic heating, power generation, wet husks composting.

\section{INTRODUCTION}

Olive oil represents a food market relevant for the European Union. $82.5 \%$ of the world olive oil production takes place in the EU27, i.e. 2.34 of 2.84 million tonnes, particularly in Spain, Italy, Greece, Portugal, France, Cyprus, Slovenia and Malta. The percentage rises to $94.1 \%$ of the world olive oil production, i.e. 2.63 million tonnes, if the Countries of the Mediterranean basin are included [1,2]. In Europe 12.76 million tonnes of olives, produced in 4.8 million hectares (Ha) under cultivation, are annually processed in ca.12.000 mills, involving 800.000 jobs [3].

Three processes are currently in use for olive oil extraction [4], i.e. the traditional process (TP), the two-phase decanter (2PDP) and the three-phase decanter process (3PDP), each of them generating different amounts of solid and liquid waste. Taking into account that solid wastes from olive oil extraction are in the range of $50-72 \%$ of the olive weight (for 3PDP and 2PDP, respectively) and that liquid waste is 83 and 972 liters per tonne of olives (2PDP and 3PDP, respectively) [5], in the EU the overall wastes produced annually from olive oil extraction are remarkable. An estimate of the wastewater and solid waste produced in the six major olive oil producing EU countries is presented

*Address correspondence to this author at the Department of Agriculture, Food and Environment (DAFE), University of Pisa, Via del Borghetto 80, 56124 Pisa, Italy; Tel: +39 050 2216647; E-mail: monica.agnolucci@unipi.it in Table $\mathbf{1}$, totalling 6.01 million $\mathrm{m}^{3}$ and 8.06 million tonnes, respectively. The estimate is based on the relative distribution of the olive oil extraction technology and on the amount of olives processed during the last five years. Higher annual figures have been presented when considering the Mediterranean basin, i.e. up to 30 million $\mathrm{m}^{3}$ of olive mill wastewater and 20 million tonnes of solid waste [6,7]. The solid waste is the residual paste generated from olive oil extraction, and is called pomace (synonyms: wet husk, virgin pomace, crude olive cake). It is a mixture of olive pit/stone, debris of olive pulp and skin, as well as pomace olive oil plus the water added in the olive mills. The moisture content is about $50-75 \%$ depending on the olive oil production process used. The solid waste generated from 2PDP after a second oil extraction is de-oiled husk (synonyms: exhausted husk, extracted husk, extracted pomace). Virgin pomace generally presents difficulties for its disposal, as it is difficult to handle due to high mill wastewater content, it dries out very slowly and, as such, is environmentally polluting [8,9]. Several methods have been proposed for the disposal, utilization, and upgrading of wet and de-oiled husk [10,11]. They include: (a) thermo-chemical processes, i.e. combustion, pyrolysis or gasification; (b) anaerobic digestion [12]; (c) alcoholic fermentation [13)]; (d) blending [14] and chemical extraction [15]; (e) agronomic: direct application by land-spreading, usage as animal feed, composting and subsequent field usage as soil amendment $[16,17]$. Due to their more widespread use in the EU, only 
Table 1. Annual Production of Olive Mill Waste Waters and Solid Waste in the Six Major EU Olive Oil Producing Countries, Based on the Distribution of the Technology of Olive Oil Extraction and on the Annual Average Production of Olives (Last Five Years)

\begin{tabular}{|c|c|c|c|c|c|c|c|c|c|c|c|}
\hline $\begin{array}{c}\text { EU } \\
\text { Country }\end{array}$ & $\begin{array}{c}\text { Olives Processed } \\
\text { (Tonnes) }\end{array}$ & $\begin{array}{c}\text { Average Production of Olive Oil } \\
\text { (Tonnes) }\end{array}$ & \multicolumn{2}{c|}{$\begin{array}{c}\text { \%Extraction } \\
\text { Technology }\end{array}$} & \multicolumn{4}{|c|}{$\begin{array}{c}\text { Waste water } \\
\left(\mathbf{m}^{\mathbf{3}}\right)\end{array}$} & \multicolumn{4}{|c|}{$\begin{array}{c}\text { Solid Waste } \\
\text { (Tonnes) }\end{array}$} \\
\hline & & & 3PDP & 2PDP & TP & 3PDP & 2PDP & TP & 3PDP & 2PDP & TP \\
\hline \hline Spain & $6,230,000$ & $1,106,460$ & 1 & 99 & & 62,431 & 527,777 & & 32,564 & $4,610,108$ & \\
\hline Italy & $3,791,400$ & 613,360 & 55 & 15 & 30 & $2,028,468$ & 47,240 & $1,106,447$ & $1,058,060$ & 412,641 & 577,128 \\
\hline Greece & $2,257,800$ & 379,590 & 82 & 18 & & $1,799,556$ & 33,731 & & 938,657 & 294,642 & \\
\hline Portugal & 213,800 & 35,680 & 12 & 4 & 84 & 24,844 & 70,716 & 173,910 & 12,958 & 6,177 & 90,712 \\
\hline Cyprus & 36,000 & 6,280 & 84 & 6 & 10 & 29,393 & 17,926 & 3,499 & 15,331 & 1,566 & \\
\hline France & 26,480 & 4,300 & 70 & 30 & & 17,962 & 65,736 & & 9,361 & 5,742 & 1,825 \\
\hline & & & & & & & & & & & \\
\hline Subtotal & & & & & & $3,962,654$ & 763,126 & $1,283,856$ & $2,066,931$ & $5,330,876$ & 669,665 \\
\hline Total & $\mathbf{1 2 , 7 4 8 , 4 8 0}$ & $\mathbf{2 , 1 4 5 , 6 7 0}$ & & & & & $\mathbf{6 , 0 0 9 , 6 3 6}$ & & & $\mathbf{8 , 0 6 7 , 4 7 2}$ \\
\hline
\end{tabular}

thermo-chemical processes and composting are considered in this study.

The olive oil industry has become of special concern in the Mediterranean basin due to (i) the amount of olives processed and the need to maintain adequate quality control measures, (ii) the amount of residues generated annually during the oil production cycle, i.e. solid and liquid wastes (wet and extracted husks, olive pits, leaves and prunings, olive mill wastewater), and (iii) the limited period of time for processing olives and disposing of wastes during the year, i.e. 2-3 months. This can lead to soil and water pollution $[18,19]$ unless appropriate life cycle management strategies are adopted, allowing a sustainable development of this important agro-food industry.

In order to evaluate the environmental aspects of the main possible streamlines for disposal of the solid residue of olive oil extraction, i.e. combustion for electricity generation, combustion for domestic heating and composting, (compost to be used as an amendment, fertilizer or to stimulate plant defences), this study was undertaken by means of Life Cycle Impact Assessment methodology allowing evaluation of the environmental impact and performances of these disposal strategies. The analysis dealt with the different methods of recovery and upgrading of the olive solid residue called "wet husks" obtained during the olive oil extraction with the two-phase decanter centrifugation. Irrespective of the country enlisted in Table 1, the 2-phase decanter centrifugation and the 3-phase or traditional extractions are the same, and the table illustrates the use of different technologies throughout the EU major oliveprocessing countries. Since wet husks, produced by the 2phase extraction process, give rise to the majority of solid residues in EU (5.3 million tons over 8 million tons on an annual basis) and since there is an increasing trend to adopt this more efficient and less expensive process in Europe and outside Europe, this technology has been taken into consideration for our study.

\section{METHODOLOGY}

The study was carried out using the software LCA SimaPro 7.2.3 [20], in agreement with ISO 14040:2006, including the data collected on-site. The LCA of olive oil was done according to the method described by Fiore $e t$ al. [21]. The latter study conformed with ISO 14040-14044, and the functional unit, useful to quantify input and output fluxes through system boundaries, was $0.5 \mathrm{~L}$ of bottled extra-virgin olive oil made ready for marketing. Ecoinvent database was used for data off-site [22]. In order to aggregate the results and obtain a unique indicator for the quantification of the overall impact, the method ReCiPe Endpoints 2009 has been used. This has allowed the development of the LCA in terms of damage assessment, normalization and weighing [21].

\section{Application Field}

Three scenarios have been compared, namely domestic heat production, electric power generation, and direct composting of wet husks. These processes represent the majority of the recovery and upgrading strategies of olive oil producing countries $[11,23]$. The solid residues would include also olive tree prunings, which are manually harvested twice a year. Most of them are burned at the roadside after harvesting, while the larger branches are mostly used for domestic heating, with a small percentage going to the wood market. These residues, when dry and ash free, have a volatiles content of $87.9 \%$ and an energy content of $18.79 \mathrm{~kJ} / \mathrm{kg}$ on dry and ash-free basis. However, not having a specific inventory of prunings, they will not be considered further in this work.

Domestic heat is produced in two steps: (a) solvent (hexane) extraction of the biomass, (b) direct combustion of the extracted pomace (10-15\% humidity) in small household burners $(\geq 100 \mathrm{~kW})$. The thermal energy is used most commonly for domestic heating and sanitary hot water. The electric power production (PP) is obtained in two steps: (a) solvent (n-hexane) extraction of the biomass to obtain 
de-oiled husk (10-15\% humidity), and (b) thermo-electrical conversion of de-oiled husk, further dried to $6 \%$ humidity, in large installations. According to Caputo et al. [7] the heating value of this matrix is $18,000 \mathrm{~kJ} / \mathrm{kg}$; it has low nitrogen and sulphur content and 4-12\% ash content. A conventional boiler and a steam turbine cycle have been considered: before feeding the boiler, the olive wet husks are dried down to $6 \%$ humidity using a recovery rotator dryer heated by the hot fumes coming from the boiler. The fumes are treated in an air pollution control section, containing a fabric filter which allows dust collection before the final discharge through the stack. The steam is fed to a power generation section constituted by a steam turbine cycle. The technology considered for obtaining electricity, after the wet husk is solvent extracted, is the Rankine vapour cycle, with generation or co-generation (heat + electricity) in electrical plants (steam conventional cycles). The optimal electrical energy plant size is between 10 to $25 \mathrm{MW}$, the normal size is $25 \mathrm{MW}$. The electric power generated, considered in this study, is the installation "Energia de La Loma Power Plant" in Villanueva del Arzobispo (Jaén, E), fed with depleted (de-oiled) olive pomace. In this plant, the biomass processed is 100,000 tons / year, with an energy production of $126,144,000 \mathrm{kWh} /$ year. The self - consumption of energy is $12,942,374 \mathrm{kWh} /$ year, and the power installed is $16 \mathrm{MW}$ [24].
Direct composting has been considered on wet husk after the olive oil extraction, with $70 \%$ humidity obtained without air-drying or forced-ventilation drying or further extraction $[25,26]$. From 1 ton of wet husk $600 \mathrm{~kg}$ of green compost $(40 \%$ humidity) can be produced in 60 days. In order to assess the environmental impact of the composting strategy, three types of replacement scenarios have been considered: (i) composting followed by delivery of the amendment in soil in order to replace the use of ammonium nitrate with equal amounts of plant nutrients; (ii) composting followed by delivery of the amendment in soil to replace the use of comparable amounts of lime and algae; (iii) composting followed by delivery of the amendment in soil to replace the use of pesticides; it is known that compost prepared from wet husk has the ability to influence the growth or suppress soil-borne plant pathogens [8, 27, 28], and an average annual rate of fungicides to control the apple scab (Kg 3.75) for one hectare of apple-tree cultivation has been considered in this study.

In addition to the above study, olive oil production was also considered for an aggregate analysis, by linking the olive oil extraction process, included in the LCA by Fiore et al. [21], up to the generation of the wet husks. The aggregate analysis also included an estimation of the environmental impact of olive cultivation up to the wet husk disposal.

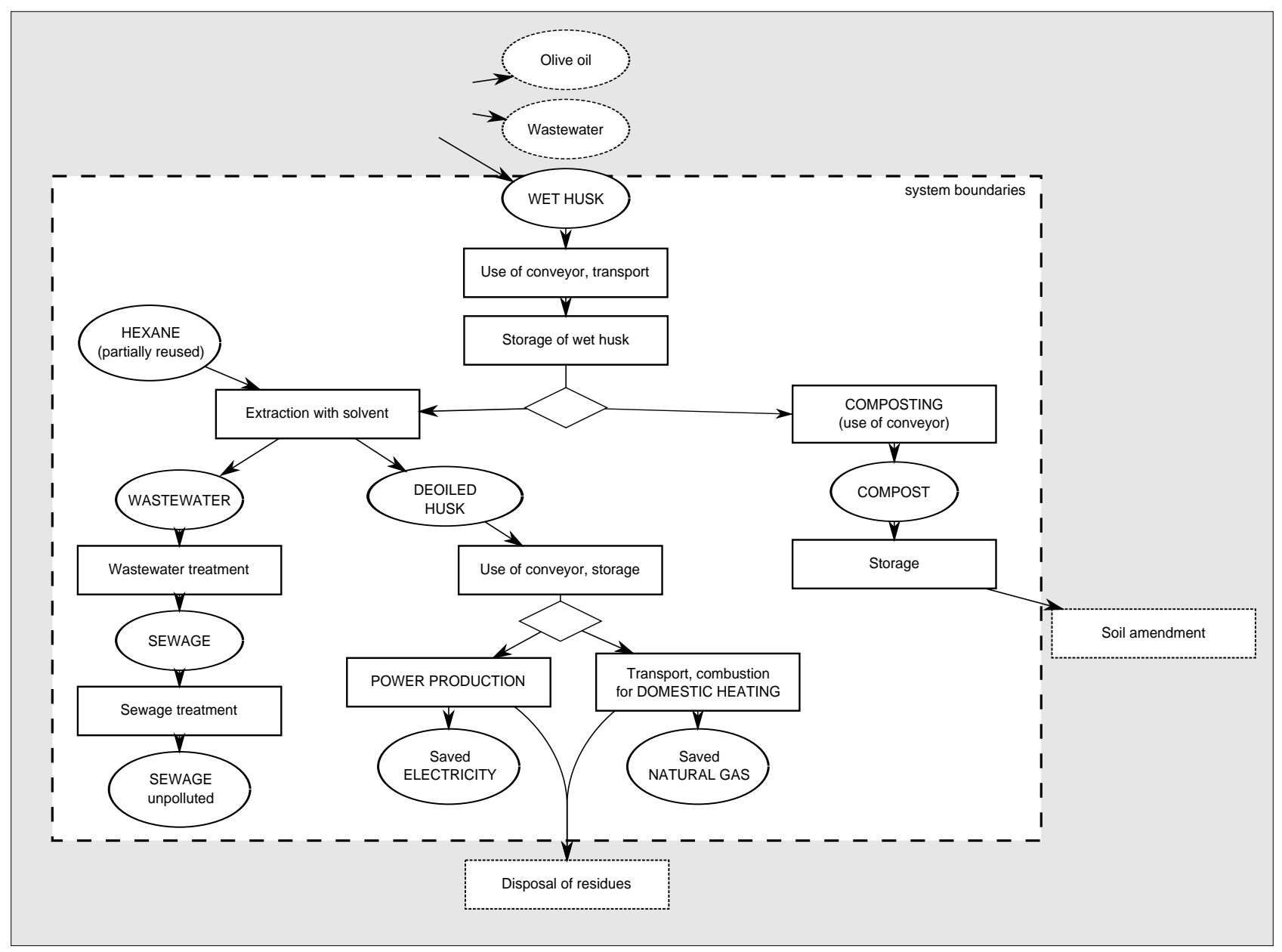

Fig. (1). System boundaries of the management of wet husks deriving from the olive oil extraction plant. The system includes three disposal strategies: generation of electricity, domestic heating and compost production. 


\section{System Boundaries}

The system boundaries include the transportation from the olive oil extraction plant to the husk processing plant, the transportation and direct combustion of de-oiled husk in household burners, the transportation and thermo-electrical conversion plant for power generation, the transportation to small/medium farms and composting in static, mechanically turned pile (Fig. 1).

Owing to the seasonality of the wet husk availability and the need to dispose of the amounts produced within the following olive oil harvest campaign, the life time of wet husk has been considered equivalent to one year. When olive oil has been considered in the analysis of aggregate scenario, the life time of the olive trees was assumed equivalent to 20 years, after which the wood was considered to be burned, outside the system boundaries (next life cycle), as indicated by the International System EPD [29].

\section{Functional Unit}

The reference unit used to quantify the fluxes within the system boundaries is one metric ton of wet husk. When the analysis takes into account the aggregate data including the Life Cycle Assessment of olive oil production, the functional unit is converted to the amount of olive oil leading to the production of 1 ton of wet husk. For the analysis of the aggregate scenario the functional unit is $0.5 \mathrm{~L}$ of extra virgin olive oil.

\section{Inventory Analysis}

Specific data from operating facilities were used where available, or literature data from sectoral studies, and otherwise the secondary data from the Ecoinvent 2.2 [22] database contained in the software Simapro 7.2.3 [20]. Storage of the olive wet husks in open air facilities was considered for an average of 90 days, and transport was within a range of $100 \mathrm{~km}$ from olive growers to extraction installation. The waste-to-energy waste disposal strategies were considered in a centralized- combined approach. Prior to solvent extraction, the wet husk ( $70 \%$ humidity) must be dried down to $6 \%$ humidity. Machinery and engines considered were those used in the most frequently adopted case, where the wet husks are fed into a rotatory dryer [30] to reduce humidity from 69 to $15 \%$ through evaporation; a further reduction to $6 \%$ humidity is obtained by using the hot gases produced by combustion of a fraction of the dried husks. A daily production of 600 tons of dried husk ready for burning can be obtained in a medium-size installation. Solvent extraction is carried out by washing the dried husk with hexane (20:1, weight/weight) to recover ca. $3 \%$ crude pomace oil. Through steam treatment of the solid residue, using a further boiler fed with de-oiled husk, the solvent is recovered and recycled within the extraction plant, with an estimated loss of $0.2 \%$ each cycle. Quantitative estimates of the production process mass flow, with reference to one tonne of treated olives, were the ones described by Caputo et al. [7], including drying, thermal or anaerobic treatment of olive husks. For composting, in the assembly phase of the raw materials, the starter was represented by $10 \%$ of composted de-oiled husk [25].

\section{LCIA: Impact Classification and Characterization}

Two impact assessment methods were used in the evaluation of the environmental impact: the Environmental Product Declaration [29] and the ReCiPe method. The EPD method does not aggregate categories, hence no weighing or normalisation was included. Characterization factors modified from version 1.02 [29] were used as follows (units): greenhouse gases ( $\mathrm{kg} \mathrm{CO}_{2}$ equivalents), ozone depleting gases ( $\mathrm{kg}$ CFC-11 equivalents), acidifying compounds ( $\mathrm{kg} \mathrm{SO} \mathrm{SO}_{2}$ equivalents), non renewable fossil energies depletion (MJ equivalents), eutrophicating compounds ( $\mathrm{kg} \mathrm{PO}_{4}{ }^{3-}$ equivalents).

The default ReCiPe endpoint method was used [ReCiPe Endpoint (H) V1.04]. Normalisation values for Europe and the average weighing set were used to arrive at single scores. ReCiPe used three main damage categories: human health, ecosystem and resources. Human health (expressed in disability adjusted life years) includes the effects of climate change on human health, ozone depletion, human toxicity, photochemical oxidant formation, particulate matter formation and ionising radiation. Ecosystems (expressed in species lost every year) include the effects of climate change on ecosystems, terrestrial acidification, freshwater eutrophication, terrestrial, freshwater and marine ecotoxicity, agricultural and urban land occupation, and natural land transformation. Resources included metal depletion and fossil depletion, expressed in US dollars.

\section{RESULTS AND DISCUSSION}

\section{Impact of Pomace Biomass on Possible End-of-Uses in EU}

In the EU northern Mediterranean countries, the overall wastes produced annually from olive oil extraction are remarkable (ca. 14 million tons of waste), causing potential environmental problems unless properly disposed or upgraded. Italy and Greece are leading for available liquid waste, i.e. $96 \%$ of the overall EU annual production, while Spain provides $57 \%$ of the overall EU solid waste. However, for the six major EU olive oil producers, there is ample space for strategic choices about the disposal of their wastes, except Spain where the technology shift has already taken place in favour of the more efficient and less-impacting 2phase decanter extraction process since the beginning of this millennium.

If a similar trend, namely a gradual disappearance of 3phase process, will be applied by the other five Countries, the amount of solid waste could then easily rise from 8 million to 12 million tons of pomace, on an annual basis. This, in turn, would provide a valuable source for both energy and agricultural uses.

Energy recovery (heat and electricity) from the olive-mill solid waste is characterized by high technological requirements, qualified personnel and high capital investment. In addition, the installation management is onerous and complex, and therefore energy recovery would be more suited for centralized approaches. The economic profitability depends on the possibility of gathering the residues of at least 200 mills and of achieving high levels of efficiency 
and reliability [7]. Unfortunately, in EU Member States there is a relevant policy fragmentation for energy recovery from wet husk, which until now has overlooked Life Cycle Environmental Impact Assessment and neglected Life Cycle Management of this quantitatively important agricultural waste. To our knowledge, only in Slovenia, and particularly in the region Istria, nearly the totality $(95.4 \%)$ of olive residues are composted and returned to the olive groves as fertilizer. The composting of olive residues is integrated in the processing cycle of each oil mill. After the 3-6 month composting period, the olive residues are spread on the surface as fertilizer, returning nutrients to the soil. Only 4.6 $\%$ of olive residues are used for energy purposes to generate heat. This amount of residue produces energy for heating two households. In Crete the vast majority of wet husk is used for domestic heat, in other EU Member States the three destinations co-exist sometimes without an apparent rationale (e.g. in Liguria region, Italy, only de-oiled pomace is authorized for household burning, but the same region lacks de-oiling industrial installations, thus forcing the use of long distance transport of de-oiled pomace).

\section{Impact of Scenarios}

The contribution of the different scenarios to the impact categories, evaluated by means of ReCiPe endpoints, is reported in Table 2. Domestic heat and power generation were the most impacting scenarios in damaging human health, ecosystems, and in natural resources depletion. Composting was 2-4 orders of magnitude less impacting than domestic heat production and power generation. The negative values in Table $\mathbf{2}$, with reference to composting, result from the ReCiPe products avoided scenarios, reported in the next chapter. For human health, the impact of climate change, the human toxicity and the particulate matter formation represented the main impact categories. For ecosystems, climate change and natural land transformation appeared to be the main impact categories. Within the natural resources depletion, the fossil energy depletion was three orders higher than metal depletion.

\section{Process Phases vs Impact Categories}

The impact assessment of the different phases of each of the scenarios, evaluated by means of EPD method, is shown in Figs. (2, 3), and 4. By analysing the domestic heating scenario, the storage of wet husk along with the extraction by organic solvent, and the waste treatment were the most impacting phases for global warming potential, ozone layer depletion, acidification and non renewable fossil fuel resources depletion. For the eutrophication, the most impacting phase was the husk wastewater treatment (Fig. 2). By analysing the power generation scenario, the impact profile was essentially the same as for the domestic heating scenario (Fig. 3). The analysis of the composting scenario (Fig. 4) indicated that waste treatment was a relevant impacting phase of the process on global warming potential, ozone layer depletion, and acidification; on the contrary, storage of wet husk and composting impacted only on global warming. Overall the two phases impacting most strongly on global warming, ozone depletion and acidification, were the storage of wet husk (which is different in the three processes) and the residual waste treatment after processing.

Within the scenario of composting olive wet husk, a comparison was carried out by means of ReCiPe endpoints method taking into account the so-called "products avoided",

Table 2. Comparison of Impacts from Different Scenarios of Olive Oil Extraction Waste Treatment. Characterization Carried Out Using the ReCiPe Endpoint Method

\begin{tabular}{|c|c|c|c|c|c|}
\hline Damage Category & Impact Category & Unit & Domestic Heating & Power Production & Composting \\
\hline \multirow{4}{*}{ Damage to human health } & Climate change Human Health & DALY & $5.46 \mathrm{E}-03$ & $5.09 \mathrm{E}-03$ & $6.81 \mathrm{E}-06$ \\
\hline & Human toxicity & DALY & $3.76 \mathrm{E}-03$ & $3.71 \mathrm{E}-03$ & $-1.35 \mathrm{E}-05$ \\
\hline & Photochemical oxidant formation & DALY & $1.04 \mathrm{E}-04$ & $1.04 \mathrm{E}-04$ & $1.18 \mathrm{E}-08$ \\
\hline & Ionising radiation & DALY & $9.45 \mathrm{E}-06$ & $8.39 \mathrm{E}-06$ & $-1.28 \mathrm{E}-07$ \\
\hline \multirow{6}{*}{ Damage to natural environment } & Climate change Ecosystems & Species per year & 3.09E-05 & $2.88 \mathrm{E}-05$ & $3.86 \mathrm{E}-08$ \\
\hline & Terrestrial acidification & Species per year & $1.50 \mathrm{E}-07$ & $1.47 \mathrm{E}-07$ & $7.89 \mathrm{E}-10$ \\
\hline & Freshwater eutrophication & Species per year & 4.14E-08 & $3.77 \mathrm{E}-08$ & $-5.99 \mathrm{E}-10$ \\
\hline & Agricultural land occupation & Species per year & $6.18 \mathrm{E}-07$ & $5.98 \mathrm{E}-07$ & $-1.97 \mathrm{E}-08$ \\
\hline & Urban land occupation & Species per year & $6.08 \mathrm{E}-07$ & $5.94 \mathrm{E}-07$ & $-4.81 \mathrm{E}-09$ \\
\hline & Natural land transformation & Species per year & $9.04 \mathrm{E}-06$ & $9.08 \mathrm{E}-06$ & $1.13 \mathrm{E}-08$ \\
\hline \multirow{2}{*}{ Damage to natural resources } & Metal depletion & $\$$ & $1.84 \mathrm{E}+01$ & $1.82 \mathrm{E}+01$ & $-5.53 \mathrm{E}-01$ \\
\hline & Fossil fuel depletion & $\$$ & $7.61 \mathrm{E}+04$ & $7.78 \mathrm{E}+04$ & $2.77 \mathrm{E}+01$ \\
\hline
\end{tabular}



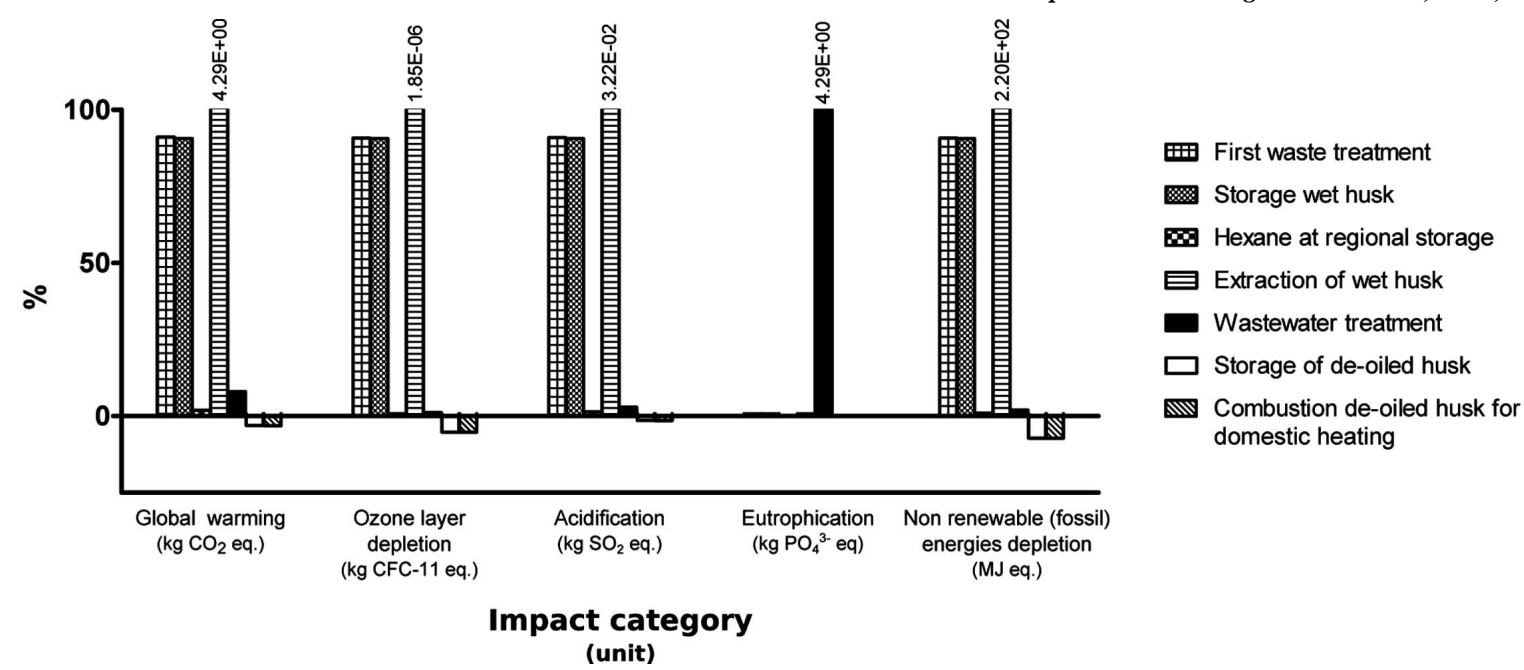

Fig. (2). Impact assessment of the different phases characterizing the disposal scenario of wet husks through domestic heating. The values on top of the $100 \%$ bars, where appropriate, are logarithmically expressed.

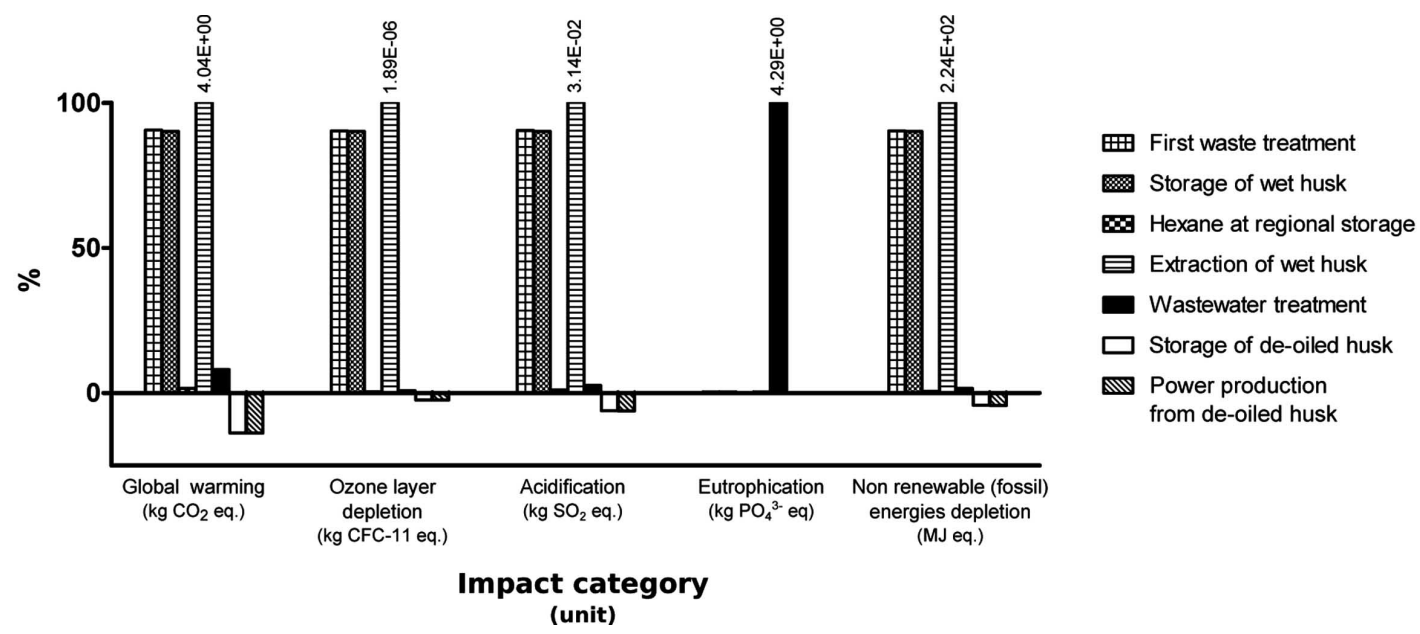

Fig. (3). Impact assessment of the different phases characterizing the disposal scenario of wet husks through generation of electricity. The values on top of the $100 \%$ bars, where appropriate, are logarithmically expressed.

namely the fertilizer equivalents expressed as ammonium nitrate or liming, and the pesticides, which can be replaced by using the compost. By analyzing the data, the contribution of the compost in lowering the impacts on human health (climate change, human toxicology and particulate matter formation) was more significant when considering the replacement of chemical nitrogen fertilizer use and, to a lesser extent, the substitution of pesticides (Fig. 5a). As for the damage to ecosystems (Fig. 5b), the use of compost instead of chemical fertilizers contributed significantly to reducing the impact on the category climate change and natural land transformation. In addition, the composting strategy encompassed storage periods of approximately three months, throughout the year, shorter than those required for the production of energy. Heating with dried pomace starts almost 9-10 months after the pomace is produced, and electricity cannot be produced until after a minimum of 6 months because wet pomace has to be stored prior to processing (i.e. drying) and stored prior to burning. As for resources depletion (Fig. 5c), the major contribution to reducing the impacts was when compost was used to replace chemical fertilizers and pesticides. In addition to the above considerations, the EU subsidies for olive growers and olive extraction enterprises are due to end by 2013 [8], and so the return of transformed olive extraction wastes, to prevent depletion of organic matter and nutrients in soils is a sustainable agricultural and economic strategy. In our study, heat and electricity production had a larger GWP than composting, which might appear unusual, since composting normally involves methane emissions. However, the larger GWP of heat and electricity production in this case was mainly due to the drying phase and organic solvent extraction phase which are both absent in the composting scenario. Indeed, wet husks are the ones processed as such, and not co-composted [26], thus avoiding methane emissions since the biotransformation is of aerobic respiratory nature, i.e. using oxygen and giving rise to carbon dioxide.

\section{Aggregate Scenario (Olive Cultivation to Pomace End- Uses)}

With the EPD methodology, an aggregate scenario has been developed by using the data of Fiore et al. [21] and our data to evaluate the impact of olive oil production (from olive tree cultivation to wet husk disposal). The functional unit used by Fiore et al. [21] has been converted into the amount of olive oil which gives 1 ton of wet husk as a waste, 


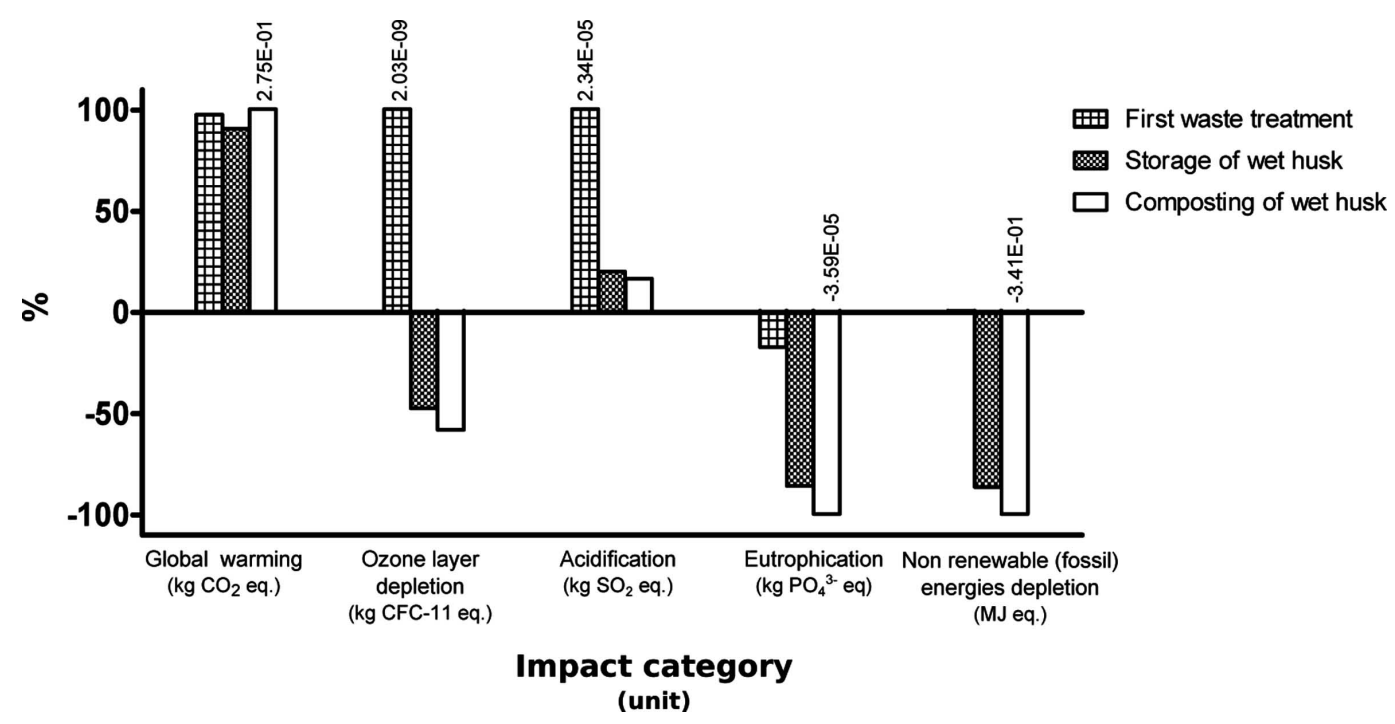

Fig. (4). Impact assessment of the different phases characterizing the disposal scenario of wet husks through direct composting. The values on top of the $100 \%$ bars, where appropriate, are logarithmically expressed.

considering the olive oil density of $0.92 \mathrm{~kg} / \mathrm{m}^{3}$ [5] and the production of $200 \mathrm{~kg}$ of oil every $800 \mathrm{~kg}$ of wet husk [23].

Analyzing the data, and taking into account the categories green-house gases, ozone depleting gases, acidifying compounds, and non renewable energy, fossil depletion (Fig. 6), the major impact in the life cycle derived from olive oil production while the disposal process was less significant. On the contrary, when eutrophication potential is considered, the disposal options "power production" and "domestic heating" affect this parameter significantly.

Recently, the LCA tools have been adopted for extra-virgin olive oil produced in small regional areas in the South of Greece [29]. The study highlights that the most important of the environmental impacts based on the functional unit (bottle of virgin oil) related mostly to the field (olive tree cultivation) phase, less to the fruit processing phase, and even less with the packing phase. The impact on eutrophication is caused primarily by leaching of fertilizers in the field phase, in particular nitrates and phosphates, and to olive extraction with the old 3-phase technology by the olive oil mills, generating large quantities of Olive Mill Waste Water (OMWW). This waste is left to dry in evaporation ponds, from where leaching is possible to the surrounding area, hence causing environmental pollution. In the cultivation phase, the impact of biogenic gas emissions can be trimmed by avoidance of wood burning and by expanding the proportion of the area under permanent no till. Considering these results, it appears that the shifting to 2-phase extraction process followed by a composting strategy of the pomace, could help minimize the eutrophication effects of nutrient leaching in soil, avoid lagooning of large volumes of wastewaters, and provide the ecosystem with more stable, humified organic carbon [26].

\section{CONCLUSIONS}

Our analysis, which compared three possible scenarios (heat, electricity and composting), indicated that composting is 2-4 orders of magnitude less impacting than domestic heat and power generation, and identified the major impact categories for each of the scenarios.
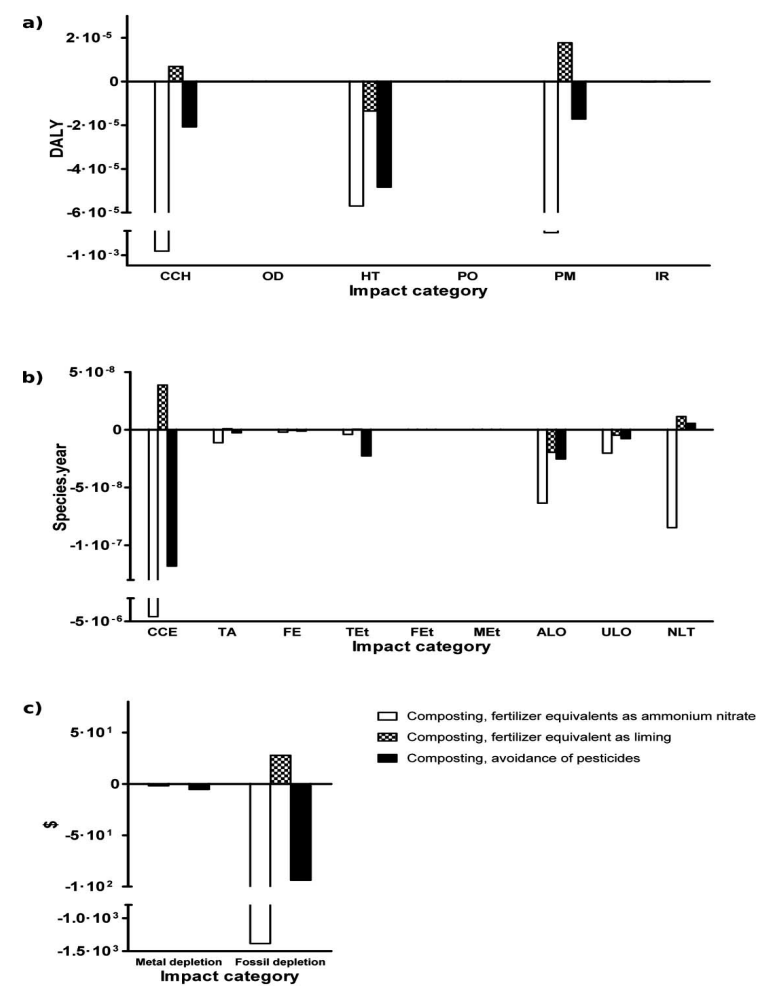

Fig. (5). Comparative impact assessment within the scenario of direct composting of the olive wet husks, taking into account the products avoided (CO-AN: fertilizer equivalents as ammonium nitrate; CO-LI: fertilizer equivalent as liming, CO-P: avoidance of pesticides). a. Damage on human health, expressed in DALY units (Disability Adjusted Life Years); this unit indicates the weight of a disability on the basis of the number of years spent having a disease or lost for premature death; b. Damage on the environment, expressed as loss of biological species per year; c. Damage on non renewable resources, expressed in US\$.

In conclusion the "composting" scenario had the least environmental impact in all of the categories studied. Furthermore, the worst scenarios ("domestic heating" and "power production") have a minimal environmental impact 


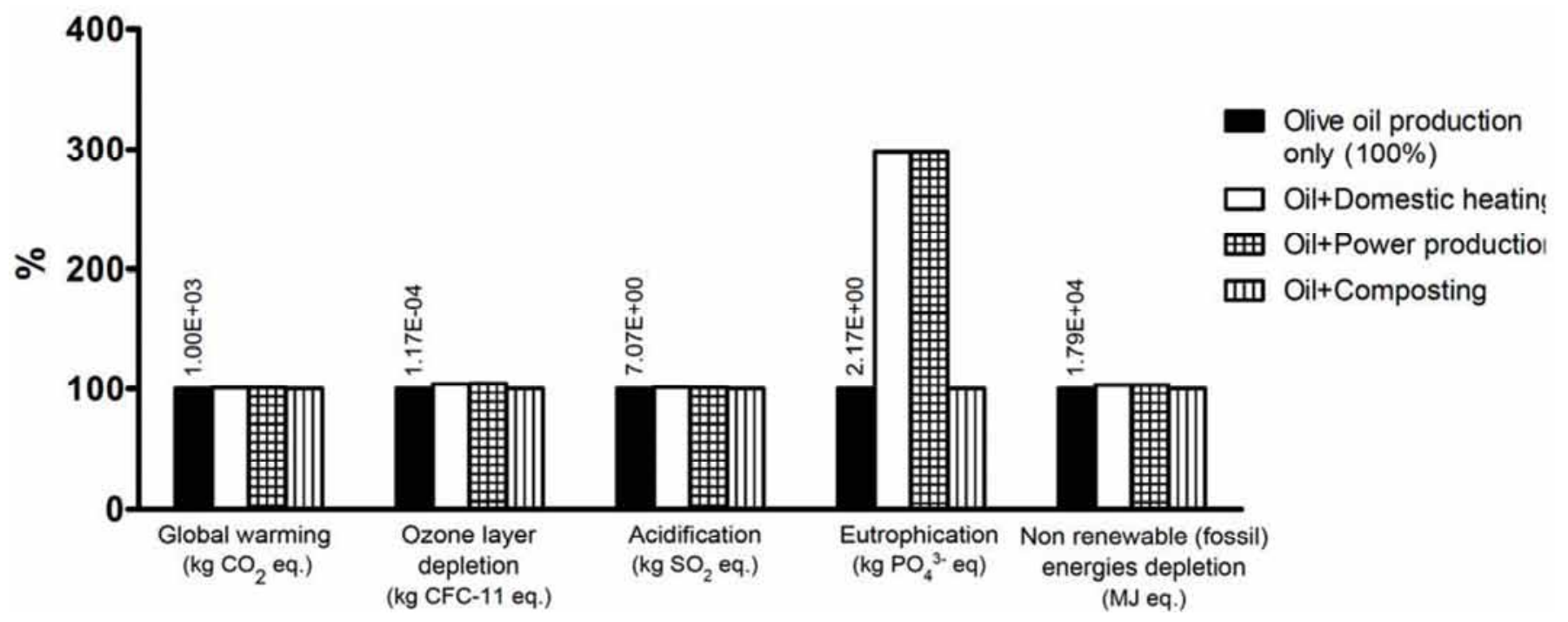

Fig. (6). Impact assessment of the aggregate scenarios including olive oil production and wet husks management.

on the overall olive oil production chain, with the exception of the "eutrophication potential". Therefore, the management of wastewater, produced from husk during the oil extraction phase, was the major critical point to be taken into account in order to minimize the environmental impact of these processes. Further comparative studies focusing on social and economic impact could help to complete the analysis of the factors affecting the Life Cycle Management of wet husk.

\section{CONFLICT OF INTEREST}

The authors declare that this article content has no conflict of interest

\section{ACKNOWLEDGMENTS}

The financial support for this research has been provided by the University of Pisa (Italy) to MN. Prof. Jeremy Sweet, Cambridge (UK) is gratefully acknowledged for critically proofreading the manuscript.

\section{REFERENCES}

[1] IOC, International Olive Council, 2009. www.internationaloliveoil. org/downloads/production2_ang.PDF [viewed on 01/06/11].

[2] OOS, Olive Oil Source. 2008. www.oliveoilsource.com/statistics. htm [viewed on 01/06/11].

[3] FAO, 2006. Food and Agriculture Organization, FAOSTAT database, www.fao.org (accessed 10.06.11)

[4] P.A. Fokaides, K. Tsiftes, "Technologies for the utilization of olive husk in the energy industry", Arab Water World, vol. XXXII, no. 8, pp. 22-23, 2008 (in English and Arabic)

[5] P. Amirante, G.C. Di Renzo, L. Di Gioacchino, B. Bianchi, P. Catalano, "Technological development in olive oil extraction plants", Olivae, vol. 48, pp. 43-53, 1993.

[6] F. Boubaker, B.C. Ridha, “ Anaerobic co-digestion of olive mill wastewater with olive mill solid waste in a tubular digester at mesophilic temperature", Biores. Technol., vol. 98, pp. 769-774, 2007.

[7] A.C. Caputo, F. Scacchia, P.M. Pelagagge, "Disposal of byproducts in olive oil industry: waste-to-energy solutions", Appl. Thermal Eng., vol. 23, pp. 197-214, 2003.

[8] G. Alfano G., G. Lustrato, G. Ranalli, "From the soil into the soil a closed cycle of olive oil residues. Future scenarios and perspectives", Dynamic Soil Dynamic Plant, vol. 5, no. 2, pp. 5157, 2011.

[9] C. de la Fuente, R. Clemente, I: Martinez-Alacalà, G.Tortosa, M.P. Bernal, " Impact of fresh and composted solid olive husk and their water-soluble fractions on soil heavy metal fractionation, microbial biomass and plant uptake", J. Haz. Mat., vol.186, pp. 1283-1289, 2011.

[10] N. Azbar, A. Bayram, A. Filibeli, A. Muezzinoglu, F. Sengul, A. Ozer, "A review of waste management options in olive oil production", Crit. Rev. Environ. Sci. Technol., vol 34, pp. 209-247, 2004.

[11] A. Roig, M. L. Cayuela, M. A. Sanchez-Monedero, "An overview on olive mill wastes and their valorization methods", Waste Manag., vol. 26, pp. 960-969, 2006.

[12] I. Ballesteros, J.M. Oliva, M.J. Negro, P. Manzanares, M. Ballesteros, "Ethanol production from olive oil extraction residue pre-treated with hot water", Appl. Bioch. Biotechnol., vol. 98, pp. 717-732, 2002.

[13] A.R. Tekin, A. C. Dalgic, "Biogas production from olive pomace", Resour. Conserv. Recycl., vol. 30, pp. 301-313, 2000.

[14] G.Siracusa, A. D. La Rosa, V. Siracusa, M. Trovato "EcoCompatible Use of Olive Husk as Filler in Thermoplastic Composites", J. Polym. Environ., vol. 9, pp. 157-161, 2002.

[15] H. K. Obied, M. S. Allen, D. R. Bedgood, P. D. Prenzler, K. Robards, "Investigation of Australian olive mill waste for recovery of biophenols", J. Agric. Food Chem., vol. 53, pp. 9911-9920, 2005.

[16] E. Bonari, L. Ceccarini, "Effetti dei reflui oleari sulla produzione di alcune colture agrarie" Effects of olive oil extraction residues on some crops, in Italian. In "I sottoprodotti dei frantoi oleari", L'Informatore agrario (Verona, Italy), Progetto editoriale PANDA, vol.3, pp.121-146, 2001.

[17] A. Saviozzi, R. Levi Minzi, R. Cardelli, A. Biasci and R. Riffaldi, "Suitability of moist olive pomace as soil amendment", Water Air Soil Poll., vol. 128, pp.13-22, 2001.

[18] G. Alfano, C. Belli, G. Lustrato, G. Ranalli, "Pile composting of two-phase centrifuged olive husks residues: technical solutions and quality of cured compost", Biores. Technol., vol. 99, pp. 46944701, 2008.

[19] I. Arvanitoyannis, S. A. Kassaveti, "Current and potential uses of composted olive oil waste", Int. J. Food Sci. Technol., vol. 42, pp. 281-295, 2007.

[20] M. Goedkoop, A. De Schryver, M. Oele, S. Durksz, D. de Roest, "Introduction to LCA with SimaPro" (Software 7.2.3), Amersfoort, The Netherlands, 2010.

[21] M. Fiore, L. Breedveld, C. Arrivas Bajardi, L. Giaimo, A. Notaro, "Certificazione ambientale di prodotti agroalimentari. LCA dell'olio d'oliva". Environmental certification of agro-food products. LCA of olive oil (in Italian), Ambiente Risorse e Salute, vol.122 (Luglio-Settembre), pp.12-20, 2009.

[22] Ecoinvent. Swiss Centre for Life Cycle Assessment, Ecoinvent 2.2 database, 2010 www.ecoinvent.ch (accessed 20.10.11).

[23] J.A. Alburquerque, J. Gonzalez, D. Garcia, J. Cegarra, "Agrochemical characterisation of "alperujo", a solid by-product of the two- 
phase centrifugation method for olive oil extraction", Biores. Technol. Vol. 91, pp.195-200, 2004.

[24] TDC-Olive Project, "Reimpiego dei Sottoprodotti Derivanti dalla Produzione di Olio e di Olive da Tavola" http://www.tdcolive.net/ documents/booklet/by\%20product\%20reusing_it.pdf., 2008 [viewed on $25 / 06 / 11]$

[25] M.C.Echeverria, R.Cardelli, S. Bedini, M. Agnolucci, C. Cristani, A. Saviozzi, M. Nuti," Composting wet olive husk with a starter based on oil-depleted husks enhances compost humification", Compost Sci. Utiliz., vol.18, pp.182-188, 2011.

[26] M.C. Echeverria, Cardelli, R., Bedini, S., Colombini, A., Incrocci, L., Castagna, A., Agnolucci, M., Cristani, C., Ranieri, A., Saviozzi, A., Nuti, M., "Microbially-enhanced composting of wet olive husks", Biores. Technol., vol. 104, pp. 509-517, 2012.

[27] G.Alfano, G., G. Lustrato, G. Lima, D. Vitullo, G. Ranalli, "Characterization of composted olive mill wastes to predict potential plant disease suppressiveness", Biol. Control, vol. 58, pp.199-207, 2011.

[28] G. Lima, D. Piedimonte, F. de Curtis, A. Abobaker-Elgelane, F. Nigro, A.M. D'Onghia, G.Alfano, G. Ranalli, “'Suppressive effect of cured compost from olive oil by-products toward Verticillium dahliae and other fungal pathogens", Acta Hortic., vol.56, pp. 585591, 2008.

[29] EPD, “ Environmental Product Declaration for one pack of 0.75 litre of extra virgin olive oil, part of 21,390 packages produced in $2010-2011$ by 68 olive growers in south Greece. Registration number S-P-00274", (www.environdec.com), 2011.

[30] IEC, International EPD Cooperation, General Programme Instructions for Environmental Product Declaration, www.environdec.com, 2007 (accessed 20.02.2011)

Received: August 31, 2013

Revised: September 17, 2013

Accepted: October 9, 2013

(c) Cossu et al.; Licensee Bentham Open.

This is an open access article licensed under the terms of the Creative Commons Attribution Non-Commercial License (http://creativecommons.org/licenses/by$\mathrm{nc} / 3.0 /$ ) which permits unrestricted, non-commercial use, distribution and reproduction in any medium, provided the work is properly cited. 